\title{
2006 HES PRESIDENTIAL ADDRESS \\ A TALE OF TWO MAINSTREAMS: \\ ECONOMICS AND PHILOSOPHY \\ OF NATURAL SCIENCE IN THE \\ MID-TWENTIETH CENTURY
}

\author{
BY \\ D. WADE HANDS
}

\section{INTRODUCTION}

HES Presidential addresses often attempt to answer a substantive question (or number of related questions) in the history of economic thought. The answers provided are not "answers" in the sense that one finds an answer to a simple numerical problem; rather they are historical narratives, stories, that bring the listener/reader to a new, and hopefully deeper, understanding of a particular author, piece of economic literature, or episode in the history of economic thought.

While answers are certainly nice, I am afraid that I will not be providing you with any in this paper. Rather, I will simply pose a particular question and explain the historical context in which the question arose. It is a question that I believe is both interesting and important, but it is one that has not been asked (at least in the way that I will ask it) within the existing literature. As a result, much of the paper will be devoted to trying to convince you there is in fact a "there," there - that there really is a particular historical "fact of the matter" that is worthy of investigation. Towards the end of the paper I will sketch a few approaches that might provide an answer to the question, but these are simply suggestive, and not exhaustive, of various storylines that might be considered.

The question is: Why did mainstream economics, circa 1945-1965, look so much like mainstream philosophy of science during the same period?

Before I begin trying to convince you that this is indeed an interesting question, it is important to clarify exactly what is not being asked. This digression is useful because there are two quite similar-sounding questions that do have well-established literatures, and I want to be clear how my topic differs from these more familiar subjects. The first one has long been the mainstay of economic methodology-the question of whether economics lived (or lives) up to the scientific standards set down by the

Department of Economics, University of Puget Sound, Tacoma, WA 98416

ISSN 1042-7716 print; ISSN 1469-9656 online/07/010001-13 C) 2007 The History of Economics Society DOI: $10.1080 / 10427710601178260$ 
philosophy of science (or any particular program within the philosophy of science). This question, a question that has played a major role in methodological writing from Hutchison (1938) through Blaug (1992), Caldwell (1994), Hausman (1992), and others - and one, I might add, that has, directly or indirectly, occupied a large amount of my own professional attention (Hands 2001) - is quite different from the question here. The methodological question asks whether economic practice conforms to what certain philosophers say about science in general, and I will focus on how the disciplines themselves compare. For example, one could note that two cultures, say A and $\mathrm{B}$, are surprisingly similar - and ask why that is the case - and that would be very different from asking whether the people in B live up to the behavioral norms recommended by those in A.

The second non-question involves a literature that I have elsewhere (Hands 1994) called the "economics of scientific knowledge" (ESK), a literature that takes economic theory as given and tries to employ it as a resource in the philosophy of science. One of the many questions addressed in this literature is whether what economists say about economic efficiency in microeconomics can be used to address questions about epistemic efficiency in science. Although this literature is neither as extensive, nor perhaps as familiar to most historians of economic thought as the traditional methodological literature, it is clearly another way that economic theory of a particular period might be related to work in the philosophy of science. But like methodology, the economics of scientific knowledge is not the issue here. To continue the analogy of the two cultures, ESK asks whether the tools found in culture B would be useful to those in A, and I am interested in the more general comparative question of how it is that A and B are similar, as a precondition to addressing the question of how they came to be that way. With this short digression about what I am not going to discuss, it is time to turn to the topic at hand.

\section{THE SIMILARITIES ARE UNCANNY}

During the 1950s both economics and philosophy of science moved from having a variety of competing approaches and research strategies to having a single, almost unanimously accepted, mainstream or standard view. In economics it was the "neoclassical synthesis" which combined neoclassical (particularly Walrasian) microeconomics with Keynesian (particularly IS-LM) macroeconomics. The synthesis provided a (seemingly) unified theoretical framework that, as Samuelson put it in his introductory text, demonstrated "that the broad cleavage between microeconomics and macroeconomics has been closed" (Samuelson 1964, p. 361). Key texts for the neoclassical synthesis include Hicks (1937, 1939), Lange (1944), Patinkin (1965), and Samuelson (1947), with Samuelson's Foundations being the most important single document. Although the literature was substantially more mathematical than the economic theory of a few decades before, and, as I define it, actually included mathematical general equilibrium theory (Arrow and Hahn 1971, Debreu 1959), it should not be viewed as just the Bourbakian high formalism of the Arrow-Debreu model (Blaug 2003). For this discussion the neoclassical synthesis essentially means what was being taught in graduate economics courses in 1965 .

In philosophy of science the relevant mainstream was the so-called logical empiricist "received view," a label popularized by Fred Suppe (1977), that combined 
elements of the 1930s logical positivism of the Vienna Circle with various modifications introduced after the locus of research (and many of the relevant scholars) moved to the United States. Key texts for the received view include Carl Hempel (1965), Ernst Nagel (1961), and Hans Reichenbach (1968). The objective of the received view was to provide a unified philosophical analysis of scientific knowledge that explicated both its logical structure and cognitive significance. Key features of the program included an emphasis on the logical structure of science, a distinction (though not always strict) between the theoretical terms/statements of a theory and its empirical/observable implications (with correspondence principles connecting the two), a concern for the structure of scientific explanation based on universal laws (the so-called Deductive-Nomological, or D-N, model of scientific explanation), and a broad commitment to the empirical character of scientific knowledge. In Stephen Toulmin's words: “At its most grandiose, the ambition was to establish epistemological foundations, not merely for individual theories ... nor merely, for an 'ideal type' of theory, but ... for positive science in its entirety" (Toulmin 1977, p. 602). During the first half of the twentieth century, scientific philosophy had been quite pluralist - with various pragmatisms playing a role in the U.S. and various interpretations of positivism, neo-Kantianism, and conventionalism competing in Europe (Cartwright et al. 1996, Friedman 1999) — but by the late 1950s a single received view had emerged that was capable of being codified in philosophy of science textbooks (Hempel 1966).

These two stabilizations took place simultaneously, primarily in the United States (with a substantive contribution from central European emigrants), and do not seem to be correlated with similar stabilizations taking place in other fields of inquiry at this particular place/time (i.e., there was not a similar stabilization taking place in physics, biology, psychology, etc.).

It is curious on the face of it that the development of these two fields occurred in such a similar manner, but the topic gets even more interesting when one looks at some of the common features in close detail. A partial list of the commonalties between mid-twentieth century mainstream economics and mainstream philosophy of science includes the following:

(1) Both fields looked to mathematical formalism to bring order to the foundations of their respective subject matter. For economics it generally involved calculus and real analysis, and for philosophy of science it was formal logic and set theory, but the notion that one underlying formal-axiomatic structure could be found to undergird all of the important ideas within the discipline (and the notion that one of the main problems with their predecessors was the lack of such formal underpinnings) was common to both fields.

To emphasize the point, compare Stephen Toulmin's statement of the "central axiom of the Viennese tradition" with Paul Samuelson's statement from the first page of Foundations:

They all assume that ... the established intellectual context of a science or scientific theory can be exhaustively represented as a "logical system"- - that is, that the theoretical concepts and conclusions of the science are related to one another, and to the observational evidence on which they are based, in a formal network of logical relations-and that the consistency, richness, and logical structure of this network 
determine the validity, and/or degree of establishment, of the theoretical concepts and conclusions in question (Toulmin 1977, p. 603).

The existence of analogies between central features of various theories implies the existence of a general theory, which underlies the particular theories and unifies them with respect to those central features. The fundamental principle of generalization by abstraction was enunciated by the eminent American mathematician E. H. Moore more than thirty years ago. It is the purpose of the pages that follow to work out its implications for theoretical and applied economics (Samuelson 1947, p. 3, emphasis in original).

(2) Both were concerned with "rationality": scientific rationality in the case of philosophy of science and economic rationality in the case of economics. The two notions of rationality have traditionally been considered quite different, with scientific rationality being a version of epistemic rationality (what it is rational to believe) and economics, at least rational choice theory, being a version of practical rationality (what it is rational to do or choose), but some version of rationality is key in both cases. As theories of rationality, both are subject to either a normative-prescriptive interpretation (what one ought to do to be economically or scientifically rational) or a positivedescriptive interpretation (what economic agents-at least most, or on average, or the representative - actually do, and what scientists — at least the best scientists — actually do). Although it is clear that most economists, during the period under discussion (or today), would defend the positive-descriptive interpretation of their science (at least as the proper goal, if not always successfully achieved) and that most philosophers of science, during the heyday of the received view (or today), would defend the normative-prescriptive interpretation of their endeavors (again, at least as the goal), it is equally clear that these issues have been hotly, and similarly, contested within the two fields. I will discuss philosophy of science first.

Although received view philosophers of science generally took the position that the discipline's main task was the justification of scientific knowledge, most also seemed to believe that the actual history of (at least great) science had in fact been consistent with the received philosophical characterization. Of course one of the main reasons for the breakdown of the received view was the general recognition, sparked by the work of Thomas Kuhn and others, that such a belief was not consistent with the historical record of (even great) science. A struggle over the proper place of the normative and the positive in the philosophy of science ensued and continues to the current day. The new temporary equilibrium within the philosophy of science seems to be that while the philosophy of science is, and must be, primarily normative-it is after all the philosophy, not the sociology or anthropology, of science-any successful theory will need to be much more sensitive to actual scientific practice than was the case with the received view.

A similar struggle has occurred within economics, but with the criticism (and the corresponding "give") going in essentially the opposite direction. Economists have traditionally insisted that economic science should be descriptive and that normative concerns about what ought to be have no place in (at least pure) economic theory. In recent years though, this traditional disavowal of the normative seems to be waning a bit among economists (at least with respect to rational choice theory). One response to 
the flood of research coming out of experimental psychology, behavioral economics, and experimental economics that emphasizes the poor fit between rational choice theory and the actual behavior of economic agents in certain, particularly laboratory, environments, has been to redeploy rational choice theory as a normative standard or baseline-a theory that tells us what economic agents ought to do in order to be rational (or behave/choose rationally) — rather than as an attempt to describe economic behavior. Although this normative interpretation of economic theory has not had the impact on economics that the descriptive history of science has had on the philosophy of science, it does emphasize the point that both are fundamentally about rationality, and that the proper characterization of the relevant notion of rationality has been contested in both fields.

(3) Both the neoclassical synthesis and the received view offered a "synthesis" that (for a while) effectively eliminated, or at least mitigated, a long-standing tension between prediction and explanation within the two fields. In philosophy of science, the tension was between a conception of science as primarily explanatory (as uncovering the deep, underlying causal mechanisms at work in the world) and the empiricist conception of science as mere re-description (as simply "saving the phenomena" by re-describing empirical observations in a more compact or useful form). Ideally science should do both, adequately explain and accurately predict, but philosophically the two views are difficult to reconcile. One seeks to go beyond the appearances to uncover the hidden causes, while the other insists that appearances are the only source of knowledge and that going "beyond" observation means doing metaphysics rather than science. Given its positivist roots, the received view was unabashedly on the side of re-description (for some this preference was grounded in empiricist foundationalism, for others it was conventionalism, and for still others it was a version of naturalism). But while mere re-description might be fine in purely academic debates, logical empiricism also had a pro-science message for the street; and one needs something deeper and more explanatory than a mere constant conjunction of sense experiences to replace either the active hand of a jealous God or of Hegel's history. Although a detailed discussion of exactly how the received view eliminated this tension is beyond the scope of the current discussion, the bottom line is that the program's concept of a universal scientific law combined with the D-N model of scientific explanation (particularly the symmetry aspects of such explanations) effectively did the trick. Scientific laws were grounded in, and obtained their cognitive significance from (and only from) empirical observation, but could be used to provide scientific explanations that provided science-based alternatives to the "explanations" that had traditionally been offered by religion, metaphysics, and other competing forms of life. A successful synthesis indeed.

In the case of economics, the synthesis actually seemed to eliminate two related tensions. The first is the tension between microeconomics and macroeconomics: specifically the potential tension between the rational choice-based economics of individual behavior and the highly aggregated theoretical framework of Keynesian macroeconomics. Of course much of the most important theoretical work during the 1950s and 1960s focused on resolving this tension by providing maximization-based microfoundations for the main theoretical constructs of Keynesian theory (consumption function, investment function, etc.). But while the neoclassical synthesis is wellknown for reconciling micro and macro, it is less recognized that it also helped 
reconcile a related tension between economics as a predictive science and economics as an explanatory science. Economists had traditionally wanted both of course, but there was often a tension between the two. In particular, the standard microeconomic model of homo economicus seemed to explain almost anything economists wanted to explain, but it consistently came up short when it was asked to make empirical predictions about the future behavior of economic agents (individually or in markets, but particularly in the former case). The then-standard Keynesian model seemed to do just the opposite. The "psychological laws," "liquidity preference," and "animal spirits" that Keynes used to explain the aggregate relationships in his theory appeared to provide very little in the way of "explanation," but they did a very good job (at least for a few decades) predicting the time path of the aggregate variables and how those variable changed with various policy regimes. The neoclassical synthesis consistently promised, and for a while seemed to effectively deliver on, the reconciliation of both of these antagonistic forces. Since the IS-LM model was just a low-dimensional case of a Walrasian system with few special assumptions, the micro inherited (or seemed to inherit) the predictive power of the macro, while the macro inherited (or seemed to inherit) the explanatory power of the micro. Much to the chagrin of Austrian and Marshallians on the micro side, and Cambridge fundamentalists and Post-Keynesians on the macro side, the "synthesis" seemed to eliminate both the micro-macro and the explanation-prediction tensions simultaneously.

(4) Related to the preceding point, it should be noted that both views had a static conception of their respective subject matter. The received view, following the Western epistemological tradition more generally, focused on what was and what was not knowledge at a particular point in time. There was, of course, a general interest among philosophers in the question of how scientific knowledge might change qualitatively over time, but despite that interest such a dynamic theory was not what philosophy of science provided; the growth of scientific knowledge was officially associated with a new theory subsuming the empirical content of its predecessor: a quantitative, rather than qualitative, change. This attitude ultimately gave way to a more dynamic concern in the post-Kuhnian era, but the main focus of the received view was the relatively static comparison of cognitively significant content.

Of course the neoclassical synthesis was also static. The relevant models on both the micro and macro side were equilibrium models and the main tool of analysis was comparative statics. The system was assumed to be in equilibrium for a particular set of parameter values and the relevant "analysis" involved changing these initial parameters (quantitatively) and recording the corresponding changes in the equilibrium values. The standard economic model consisted (and for that matter still consists) of three parts: primitives, parameters, and (dependent) variables. A comparative statics exercise involved determining how the dependent variables change as a result of a change in the parameters with the primitives held constant. Qualitative changes in the primitives - tastes (utility functions) on the demand side or technology (production functions) on the supply side-may have an impact the economy or model in question, but explaining the impact of such changes is not the responsibility of economic theory. Research in behavioral economics, evolutionary economics, and other fields has started to change this, but these are relatively recent developments.

(5) The previous discussion of comparative statics brings out another common feature; both of the programs differentiate their own spheres of analysis from that 
of psychology and sociology in the same way. Let me start with the more familiar case of economics. As noted above, the neoclassical tradition starts with tastes and technology as given primitives; they may be important to economic activity, but they are not things to be explained by economic analysis. Although the exogeneity of tastes and technology is well-known feature of neoclassical economics, the same applies to IS-LM Keynesian macro as well. The various propensities and preferences that lie behind the aggregate relationships in such Keynesian models are as much outside the economic analysis, and determined by psychological and sociological factors, as they are in Walrasian theory. Such givens change, but why and how they do so are not legitimate questions for either Keynesian or Walrasian theory.

Received view philosophy of science, following Reichenbach (1938), treats the relationship between the "logic of discovery" and the "logic of justification" in precisely the same way: "problems in the context of discovery properly are the concern of psychology and history, not philosophy; epistemology is occupied only with the context of justification" (Suppe 1977, p. 115). Philosophy of science is concerned exclusively with problems of philosophical justification-the logic and cognitive significance of a scientific hypothesis, empirical confirmation, scientific explanation, and such-exactly how someone came up with a particular scientific hypothesis in the first place is not the subject of philosophical analysis. Like the preferences of Walrasian agents, the received view takes such things as given, to be explained, if at all, by psychology or social conditions, and not subject to rational analysis.

(6) The rise to dominance of these two views was preceded by a period of relative pluralism and the absence of any single unified mainstream (Morgan and Rutherford 1998), but in the United States both views displaced a specific endemic research program: pragmatism in the case of philosophy of science and institutionalism in the case of economics. In both cases the previous program had been much less cohesive than that which replaced it, but nonetheless there did exist a previous intellectual framework that was displaced (in part by absorption) by the rise to dominance of these two programs. This would not count for much as a common feature-after all every program displaces something that came before-it if were not for the fact that pragmatism and institutionalism were such interconnected sets of ideas. There is, of course, a connection between the ideas of John Dewey and Thorstein Veblen, but there were also many other linkages between pragmatic philosophy and institutionalist economics: with institutionalists often drawing philosophical inspiration from pragmatism and pragmatism often looking to institutionalism for guidance in political economy (e.g., Yonay 1998). If one takes the admittedly controversial position of linking pragmatism and institutionalism into single social philosophy, then the received view and the neoclassical synthesis replaced essentially the same set of ideas. Much of the recent work on the rise of logical empiricism within the literature on the history of philosophy (Howard 2003, Richardson 2002, 2003) emphasizes precisely this political-economic character of the transition from pragmatism to the received view.

(7) Finally, it is clear the Cold War mattered to both the neoclassical synthesis and the received view. Defeating communism and the successful promotion of capitalist democracy required victory in economics and in science (Amadae 2003, Bernstein 2001, Reisch 2005). The enemy both advocated an alternative economic system and threatened with advanced scientific weapons. Victory required an economy 
that could be scientifically managed at the macro level, but still remain fundamentally grounded in free market institutions, as well a system for generating scientific knowledge that could be directed in the national interest, while still nurturing the unfettered creativity of the individual scientist. The neoclassical synthesis and the received view both served admirably to this end.

These seven points are only a sample of the various connections and common features that could be cited as similarities in the two research programs, but even if one is not willing to accept everything I have mentioned, there still seems to be something very curious here that needs to be explained. So I repeat the question: Why is it that mainstream economics and mainstream philosophy of science during this period look so much alike?

\section{A BRIEF LOOK AT SOME POTENTIAL EXPLANATIONS OF THESE SIMILARITIES}

As I said in the beginning, I will not attempt to provide a detailed answer to this question: in part because my goal here is simply to make you aware that there is an interesting historical question that is in need of an explanation and in part because I do not have, at this point, a fully fleshed out story. I do have some ideas though, some starting points, and I would like to close by briefly discussing three of these ideas. These three story lines are a blend of my own ideas as well as arguments borrowed, or culled together, from other authors (both inside and outside of the history of economic thought).

\section{The Vienna Circle Connection}

The "roots" of both the received view and the neoclassical synthesis (and least the microeconomic portion of the neoclassical synthesis) go back to the Vienna Circle in the 1930s, and perhaps this is the answer to the question. Perhaps the two disciplines have so much in common because they have common origins in the Vienna Circle. There is an extensive literature in the history of economic thought that examines the influence of the 1930s Viennese intellectual context on the development of mathematical economics - Craver (1986), Leonard (1995, 1998), Punzo (1991), Weintraub (1983) and others - as well as an extensive recent literature on the relationship between the social and economic context of interwar Vienna and the ideas of particular philosophers of science (Cartwright et al. 1996, Hocohen 2000). Although none of these authors have directly addressed the question at hand, it seems that a Viennese common origins story would be fairly easy to construct. It was not simply that the two most famous seminars, Karl Menger's mathematical colloquium on the economics side and Moritz Schlick's Thursday evening seminar on the philosophy side, were there, but rather that it was an environment awash in intellectual connections and associations, "a number of interlinked groups, with individuals often belonging to several circles, ranging from the formal gatherings of the Viennese Economic Society at the offices of the National Bankers Association, to the evening discussions at the Reichsrat Café" (Leonard, 1995, p. 742). It was one of the most important 
time-place combinations in the history of Western intellectual life: a hotbed of social, political, scientific, and philosophical thought, and it was an environment without the disciplinary boundaries that demarcated economics and philosophy of science years later. Surely such things mattered in the development of two fields of inquiry with so much in common.

\section{The Harvard Connection}

A second common origins story could be told that would place the stabilization of the received view in the same place (Harvard) and same time (1939-41) that Samuelson was finishing Foundations. Roy Weintraub (1991) has examined the influence of the Harvard context on Samuelson, particularly the impact of E. B. Wilson and Lawrence J. Henderson's Pareto circle, and the philosopher Gary Hardcastle (2003) has made a strong case that Harvard in the fall 1940 represented a key moment in the ascent of logical empiricism to the status of professional philosophy of science. Harvard had hosted the Fifth International Congress for the Unity of Science in 1939 and had on its staff (visiting and permanent) a large number of the key figures in logical empiricism, but Hardcastle's main emphasis is on the Science of Science Discussion Group (SSDG) organized in the fall of 1940, primarily by Stanley S. Stevens, but also involving Rudolf Carnap, Herbert Feigl, Joseph Schumpeter, and many others. Although the Hardcastle list of participants, obtained from the Stevens's papers, does not include Samuelson's name, the number of people involved in the discussion group that have a connection to Samuelson is quite extraordinary. For example, both Joseph Schumpeter and Gottfried Haberler, were involved in the group, as were Harvard Society Junior Fellows W. V. O. Quine and Garrett Birkhoff. Samuelson had an obvious connection to the two economists, and he has frequently gone out of his way to mention both Quine and Birkhoff when discussing this period of his life (Samuelson 1998, p. 1377; Weintraub 1991, p. 64).

Another important connection between Samuelson and the SSDG involves operationalism. Samuelson's commitment (in statement if not in deed) to operationalism is well-known and has been much discussed in the secondary literature (e.g., Hands 2004, Hausman 1992, Lewin 1996, Wong 2006). What has not been noted is the operationalist hothouse environment that existed at Harvard at the time Samuelson was finishing Foundations (technically the book was finished after he moved to MIT, but as he put it "I have always insisted that Foundations was formulated on Harvard grounds" (Samuelson 1998, p. 1377)). Not only was the person most responsible for operationalism, Percy Bridgman (1927), at Harvard at the time (Moyer 1991) and involved with the SSDG, he also gave a paper in the group's very first meeting October 31, 1940 (Hardcastle 2003, p. 1973). Stanley Stevens was of course also there-recall he was the main organizer for the SSDG-and he is the person most frequently credited (if that is the right word) for bringing operationalist ideas to the human sciences (in Stevens 1939). Although Samuelson may have been introduced to operationalism at Chicago-Schultz has cited Bridgman as early as 1928 (Schultz 1928) and Samuelson mentioned operationalism in published work as early as 1938 - it seems very unlikely that an economist who titled his dissertation "The Operational Significance of Economic Theory" (Samuelson 1947, p. vii) and 
spent his life praising operationalism, would not have been influenced by the events going on at Harvard when he was a junior fellow, and orchestrated, to a great degree, by those most responsible for making "operationalism" a respectable position within the philosophy of science.

Although it certainly seems obvious that one could construct a Harvard 1937-1941 (or even just SSDG) common origins story, it is important to note that since almost everyone involved was broadly positivist in their philosophical preferences-and many had actually been members of the Vienna Circle-the Harvard commonorigins story could very well be an extension, or scene-change, in the Vienna-based story, rather than an entirely separate explanatory narrative.

\section{The Operations Research Connection}

A different, and later, common origins story has been told by Philip Mirowski (2004, 2005). Mirowski's main concern is how the received view philosophy of science came to have its particular conception of "the social" (and why that concept looked so neoclassical). His argument is, basically, that philosophers got it from their involvement in Operations Research (OR) during, and in the years immediately following, World War II. Scientists, economists, political scientists, and philosophers all worked together at places like RAND and the particular constellation of forces at work in that OR environment contributed to a particular intellectual vision that affected, and conditioned, both economics and philosophy of science. These various forced included but were not restricted to: the imperatives of funding and professional opportunity, the cultural backgrounds of the scholars involved (in particular, the high numbers of Central European emigrants), the need to balance the command-andcontrol of military structure with the values of the capitalist democracy (that the military was supposed to be defending), and the development of a common set of mathematical tools (in optimization theory, formal logic, and statistical inference). As Mirowski explains:

OR provided much of the metallic durability and intellectual firepower for postwar American social sciences such as decision theory ... and neoclassical economics; but it also provided the framework for Cold War philosophy of science.

I do not intend this thesis ... to be regarded as trafficking in vague "influences"... I am instead pointing out that the professionalization of American philosophy of science in the immediate postwar era grew directly out of the soil of Operations Research; that major figures of the logical empiricist movement in America served their country in dual capacities as operations researchers; that the editors of the flagship journal Philosophy of Science in the critical transition period, C. West Churchman (1951-1959) and Richard Rudner (1960-1975), were better known as operations researchers; that philosophers of science were employed at major OR research centers such as RAND (Mirowski 2004, p. 301).

Although Mirowski has emphasized the specific role of OR more than other authors, his general argument is consistent with recent studies in the history of economic thought such as Amadae (2003) and Bernstein (2001), and in the history of philosophy such as Reisch (2005). 
As mentioned at the end of the Harvard discussion above, the story of these influences need not be mutually exclusive (it could meld these various influences into a single, albeit quite complex, story). Many of the philosophers involved in OR had also been associated with the Vienna Circle-Mirowski and Reisch both discuss Carnap and Reichenbach in this regard - and many were also involved in the Harvard SSDG (Quine is particularly noticeable). Of course, a large number of economists were involved in OR in general and RAND in particular (Mirowski 2002), but it is important to note that Samuelson was also a member of this group. In a recent interview Samuelson even admitted to authoring one of the most important documents of Cold War science policy: "Actually, toward the end of World War II, when victory was no longer in doubt, I was lent by the Radiation Laboratory to help the Vanevar Bush Secretariat draft Science, the Endless Frontier" (Samuelson in Barnett 2004, p. 531).

\section{CONCLUSION}

So how do I see the bottom line on all this? Well, it seems that we have at least three reasonably persuasive story lines (and of course there may be more). All three are a version of the common origins story, but all have an air of functionalism about them, and each points toward different elements in my set of seven common features. It also seems that while each of these story lines is separable from the other two, and that a narrative can (and in some cases has) been constructed that emphasizes one at the expense of the others, it is also quite clear that they need not be separate. It seems that a story could be told about how these two mainstreams came to look so much alike; it starts in Vienna, passes through Harvard in 1940, and finally gets redirected and reconfigured by OR and the Cold War in the 1950s.

My goal was to start a conversation about a particular piece of intellectual history involving economics and philosophy of science, and I hope that I have done so. I have tried to persuade you that the similarities between received view philosophy of science and mainstream economics during the same period are really quite extraordinary and are badly in need of an explanation. I have also suggested a few of the paths down which such an explanation might proceed but did not provide a complete story. Since I personally find the question quite fascinating, I will continue to work on my own version of the story. I encourage those of you who are (now) interested to do the same.

\section{REFERENCES}

Amadae, Sonja A. (2003) Rationalizing Capitalist Democracy: The Cold War Origins of Rational Choice Liberalism (Chicago: University of Chicago Press).

Arrow, Kenneth J. and Hahn, F. H. (1971) General Competitive Analysis (San Francisco: Holden-Day). Barnett, William A. (2004) An Interview with Paul Samuelson, Macroeconomic Dynamics, 8 (September), pp. 519-42.

Bernstein, Michael (2001) A Perilous Progress: Economics and Public Purpose in Twentieth Century America (Princeton, NJ: Princeton University Press).

Blaug, Mark (1992) The Methodology of Economics: Or How Economists Explain, 2nd edition (Cambridge: Cambridge University Press). 
Blaug, Mark (2003)The Formalist Revolution of the 1950s, Journal of the History of Economic Thought, 25 (June), pp. 145-56.

Bridgman, Percy W. (1927) The Logic of Modern Physics (New York: Macmillan).

Caldwell, Bruce J. (1994) Beyond Positivism: Economic Methodology in the Twentieth Century, 2nd edition (London: Routledge).

Cartwright, Nancy; Cat, Jordi, Fleck, Lola, and Uebel, Thomas (1996) Otto Neurath: Philosophy Between Science and Politics (Cambridge: Cambridge University Press).

Craver, Earlene (1986) The Emigration of the Austrian Economists, History of Political Economy, 18 (Spring), pp. 1-32.

Debreu, Gerard (1959) Theory of Value (New York: Wiley).

Friedman, Michael (1999) Reconsidering Logical Positivism (Cambridge: Cambridge University Press).

Hacohen, Malachi Haim (2000) Karl Popper-The Formative Years 1902-1945: Politics and Philosophy in Interwar Vienna (Cambridge: Cambridge University Press).

Hands, D. Wade (1994) The Sociology of Scientific Knowledge and Economics: Some Thoughts on the Possibilities, in: New Perspectives in Economic Methodology, R. Backhouse (Ed) (London: Routledge), pp. 75-106. Reprinted in: Science Bought and Sold: Essays in the New Economics of Science, Philip Mirowski and Esther-Mirjam Sent (Eds) (University of Chicago Press, 2002), pp. 15-48.

Hands, D. Wade (2001) Reflection Without Rules: Economic Methodology and Contemporary Science Theory (Cambridge: Cambridge University Press).

Hands, D. Wade (2004) On Operationalisms and Economics, Journal of Economic Issues, 38 (December), pp. 953-68.

Hardcastle, Gary L. (2003) Debabelizing Science: The Harvard Science of Science Discussion Group, 1940-41, in: Logical Empiricism in North America, G. L. Hardcastle and A. W. Richardson (Eds) (Minneapolis, MN: University of Minnesota Press), pp. 170-96.

Hausman, Daniel M. (1992) The Inexact and Separate Science of Economics (Cambridge: Cambridge University Press).

Hempel, Carl G. (1965) Aspects of Scientific Explanation and Other Essays in the Philosophy of Science (New York: The Free Press).

Hempel, Carl G. (1966) Philosophy of Natural Science (Englewood Cliffs, NJ: Prentice-Hall).

Hicks, John R. (1937) Mr. Keynes and the Classics, Econometrica, 5 (April), pp. 147-59.

Hicks, John R. (1939) Value and Capital (Oxford: Clarendon Press).

Howard, Don (2003) Two Left Turns make a Right: On the Curious Political Career of North American Philosophy of Science in Midcentury, in: Logical Empiricism in North America, G. L. Hardcastle and A. W. Richardson (Eds) (Minneapolis, MN: University of Minnesota Press), pp. 25-93.

Hutchison, Terence (1938) The Significance and Basic Postulates of Economic Theory (London: Macmillan).

Lange, Oscar (1944) Price Flexibility and Employment (Bloomington, IN: Principia Press).

Leonard, Robert J. (1995) From Parlor Games to Social Science: Von Neumann, Morgenstern, and the Creation of Game Theory 1928-1944, Journal of Economic Literature, 33 (June), pp. $730-61$.

Leonard, Robert J. (1998) Ethics and the Excluded Middle: Karl Menger and Social Science in Interwar Vienna, Isis, 89 (March), pp. 1-26.

Lewin, Shira B. (1996) Economics and Psychology: Lessons from Our Own Day From the Early Twentieth Century, Journal of Economic Literature, 34 (September), pp. 1293-323.

Mirowski, Philip (2002) Machine Dreams: Economics Becomes a Cyborg Science (Cambridge: Cambridge University Press).

Mirowski, Philip (2004) The Scientific Dimensions of Social Knowledge and Their Distant Echoes in 20th-Century American Philosophy of Science, Studies in History and Philosophy of Science, 35 (June), pp. 283-326.

Mirowski, Philip (2005) How Positivism Made a Pact with the Postwar Social Sciences in the United States, in: The Politics of Method in the Human Sciences: Positivism and its Epistemological Others, G. Steinmetz (Ed) (Durham, NC: Duke University Press), 142-72. 
Morgan, Mary S. and Rutherford, Malcolm (Eds) (1998) From Interwar Pluralism to Postwar Neoclassicism (Supplement to HOPE, Vol. 30) (Durham, NC: Duke University Press).

Moyer, Albert E. (1991) P. W. Bridgman's Operational Perspective on Physics, Studies in History and Philosophy of Science, 22 (June), pp. 237-58.

Nagel, Ernst (1961) The Structure of Science: Problems in the Logic of Scientific Explanation (New York: Brace \& World).

Patinkin, Don (1965) Money, Interest and Prices: An Integration of Monetary and Value Theory, 2nd edition (New York: Harper \& Row).

Punzo, Lionello F. (1991) The School of Mathematical Formalism and the Viennese Circle of Mathematical Economists, Journal of the History of Economic Thought, 13 (Spring), pp. 1-18.

Reichenbach, Hans (1938) Experience and Prediction: An Analysis of the Foundation and Structure of Knowledge (Chicago: University of Chicago Press).

Reichenbach, Hans (1968) The Rise of Scientific Philosophy (Berkeley, CA: University of California Press).

Reisch, George A. (2005) How the Cold War Transformed Philosophy of Science: To the Icy Slopes of Logic (Cambridge: Cambridge University Press).

Richardson, Alan W. (2002) Engineering Philosophy of Science: American Pragmatism and Logical Empiricism in the 1930s, Philosophy of Science, 69 (September), pp. S36-S47.

Richardson, Alan W. (2003) Logical Empiricism, American Pragmatism, and the Fate of Scientific Philosophy in North America, in: Logical Empiricism in North America, G. L. Hardcastle and A. W. Richardson (Eds) (Minneapolis, MN: University of Minnesota Press), pp. 1-24.

Samuelson, Paul A. (1938), The Empirical Implications of Utility Analysis, Econometrica, 6 (October), pp. 344-56.

Samuelson, Paul A. (1947) Foundations of Economic Analysis (Cambridge, MA: Harvard University Press).

Samuelson, Paul A. (1964) Economics: An Introductory Analysis, 6th edition (New York: McGraw Hill).

Samuelson, Paul A. (1998) How Foundations Came to Be, Journal of Economic Literature, 36 (September), pp. 1375-86.

Schultz, Henry (1928) Rational Economics, The American Economic Review, 18 (December), pp. 643-48.

Stevens, Stanley S. (1939) Psychology and the Science of Science, Psychological Bulletin, 36, pp. 221-63.

Suppe, Frederick (1977) The Structure of Scientific Theories, 2nd edition (Urbana, IL: University of Illinois Press).

Toulmin, Stephen (1977) The Structure of Scientific Theories, in: The Structure of Scientific Theories, 2nd edition, F. Suppe (Ed) (Urbana, IL: University of Illinois Press), pp. 600-14.

Weintraub, E. Roy (1983) On the Existence of Competitive Equilibrium: 1930-1954, Journal of Economic Literature, 21 (March), pp. 1-39.

Weintraub, E. Roy (1991) Stabilizing Dynamics: Constructing Social Knowledge (Cambridge: Cambridge University Press).

Wong, Stanley (2006), The Foundations of Paul Samuelson's Revealed Preference Theory, revised (London: Routledge).

Yonay, Yuval P. (1998) The Struggle Over the Soul of Economics: Institutionalist and Neoclassical Economists in America Between the Wars (Princeton, NJ: Princeton University Press). 
